\title{
HET EILAND SABA EN ZIJN BEWONERS
}

DOOR

JHR. W. DE BRAUW

Gewezen pl. gezaghebber van Saba

Het eiland Saba behoort met de eilanden St. Martin en St. Eustatius tot onze drie bovenwindsche eilanden van het gebiedsdeel Curaçao in Nederlandsch West-Indië. Het is het kleinste in oppervlakte, nl. 13 K.M. ${ }^{2}$, en had in het jaar 1933 een bevolking van ongeveer 1450 zielen. Saba is een rotseiland. Het eiland stijgt met zijn machtige rotsen bijkans steil uit zee op. Zijn hoogste berg, ,the big mountain”, is ongeveer 850 meter hoog. De top is bijna voortdurend in een wolk gehuld, en wanneer men met de stoomboot van de Koninklijke Nederlandsche Stoomboot Maatschappij, welke maatschappij een veertiendaagschen dienst tusschen Curaçao en de drie bovenwindsche eilanden onderhoudt, het eiland van de verte uit aan den horizont ziet opdoemen, lijkt daar in zee een machtige vulkaan te liggen met een rookpluim om zijn top. Dichterbij gekomen, ziet alles er meer ongevaarlijk uit. De rookpluim blijkt een wolk te zijn, waarin de top van den grooten berg zich hult. Zooals bekend mag worden verondersteld, is het eiland Saba in vroeger tijd een groote werkende vulkaan geweest.

Volgens een bestaande theorie zou van de vier thans aanwezige dorpen op Saba het dorp „the Bottom” (250 meter boven den zeespiegel gelegen) in een der vroegere kraters van den vulkaan liggen. Als bewijs voor deze theorie wijst men op de van dezen vroegeren krater uitloopende twee uitgangen naar zee, nl. één naar de Fortbaai in het Zuiden en één naar de Ladderbaai in het Westen. Deze twee uitgangen zouden dan de uitlaten zijn, waarlangs de lava zich een weg naar buiten heeft gebaand. In hoeverre deze theorie juist is, kan niet met zekerheid worden vastgesteld. In elk geval is langs de Ladderbaai duidelijk aan het gesteente der rotsen te zien, dat deze zijn samengesteld uit hard geworden lava. Een tweede theorie is, dat de oude krater 
of kraters zich zouden bevinden in den top van den grooten berg. Inderdaad bevinden zich hier ook een grootere en een kleinere krater, waarin thans een bananenbosch welig groeit. Een bewijs verder van Saba's vroeger bestaan als vulkaan is zijn zeer vruchtbare bodem. Een voldoende regenval zorgt er verder voor, dat de vele planters op het eiland op hun gronden steeds genoegzame voorraad land- en tuinbouwproducten oogsten om hun gezin van voedsel te voorzien.

Alvorens verder uit te weiden over de thans op het eiland Saba wonende en werkende bevolking, is het wel van belang iets te vertellen over de vroegere historie van het eiland ${ }^{1}$ ). Ook in verband met den oorsprong der afstamming van de tegenwoordige bevolking, is het noodig iets van de geschiedenis van het eiland te weten. Voornamelijk is het tijdperk van begin 1600 tot 1700 van belang, met betrekking tot de vele oorlogen, welke de Republiek der Zeven vereenigde Nederlanden toen, ook in overzeesche gewesten, had te voeren.

Als eerste symptoom van de verschijning der Hollanders in de buurt van de Bovenwindsche Eilanden is de vermelding in 1626 van koopvaardijkapitein Pieter Pietersz. Heijn, varende langs de eilanden St. Eustatius en Saba. In 1636 wordt aan Jan Snouck en aan Lettré verlof verleend door de Kamer van Zeeland om van St. Eustatius bezit te nemen. Later geschiedde hetzelfde met Saba en St. Martin. Men kan dus als vaststaand aannemen, dat er vóór het jaar 1636 reeds nederzettingen van Hollanders op elk der drie bovenwindsche eilanden waren. Op elk dezer eilanden werden z.g. ",patroons" aangesteld, die namens de West-Indische Compagnie het gezag voerden.

Er is een Engelsch bericht, dat het eiland Saba bevolkt was door Hollanders en Franschen, doch de meeste schrijvers over West-Indië zijn het er over eens, dat Saba werd gekoloniseerd door ingezetenen van St. Eustatius. De ,patroons” van St. Eustatius beweerden ook recht te hebben op Saba. In 1671 wordt het eerst melding gemaakt van een „Commandeur” over St. Eustatius en Saba.

In 1665 nemen de Engelschen bezit van Saba, nadat dit eiland en St. Eustatius 30 jaren in het vreedzaam bezit van de daar gevestigde kolonisten waren geweest. De op Saba wonende Hollanders werden naar St. Martin overgebracht.

In 1667 heroverde John Sympson, commandeur van St. Mar-

1) De meeste geschiedkundige gegevens zijn ontleend aan $\mathrm{De} \mathrm{Neder-}$ landers op de West-Indische Eilanden door J. H. J. Hamelberg. 


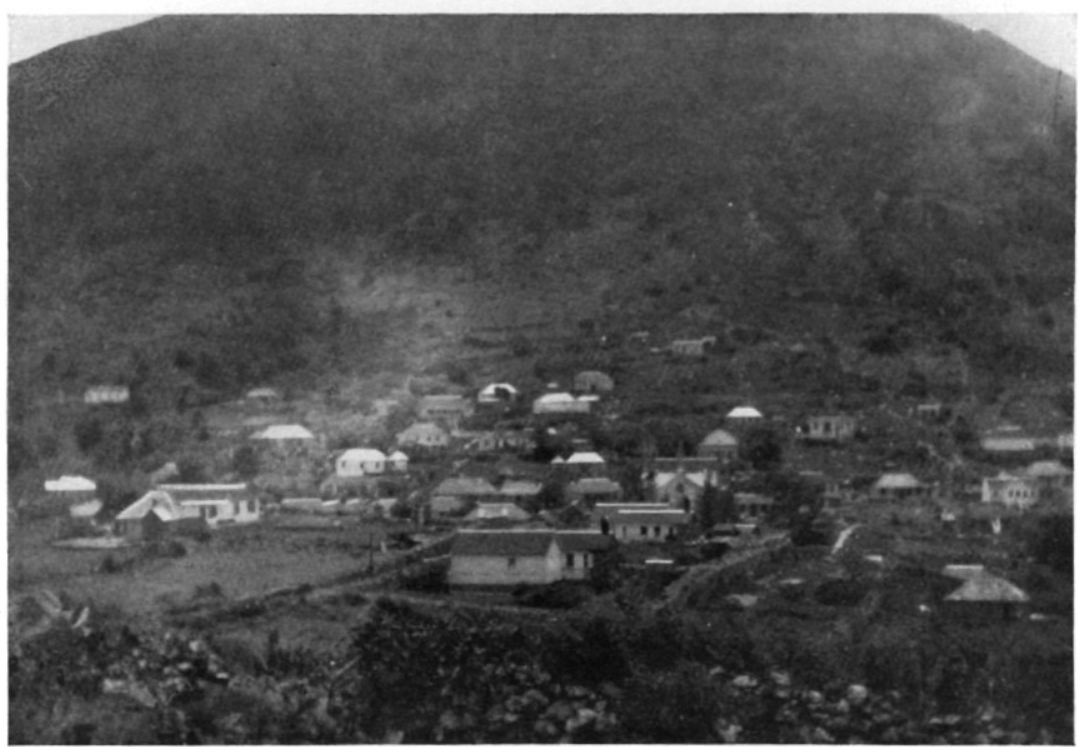

Fig. I. Het dorp Windwardside.

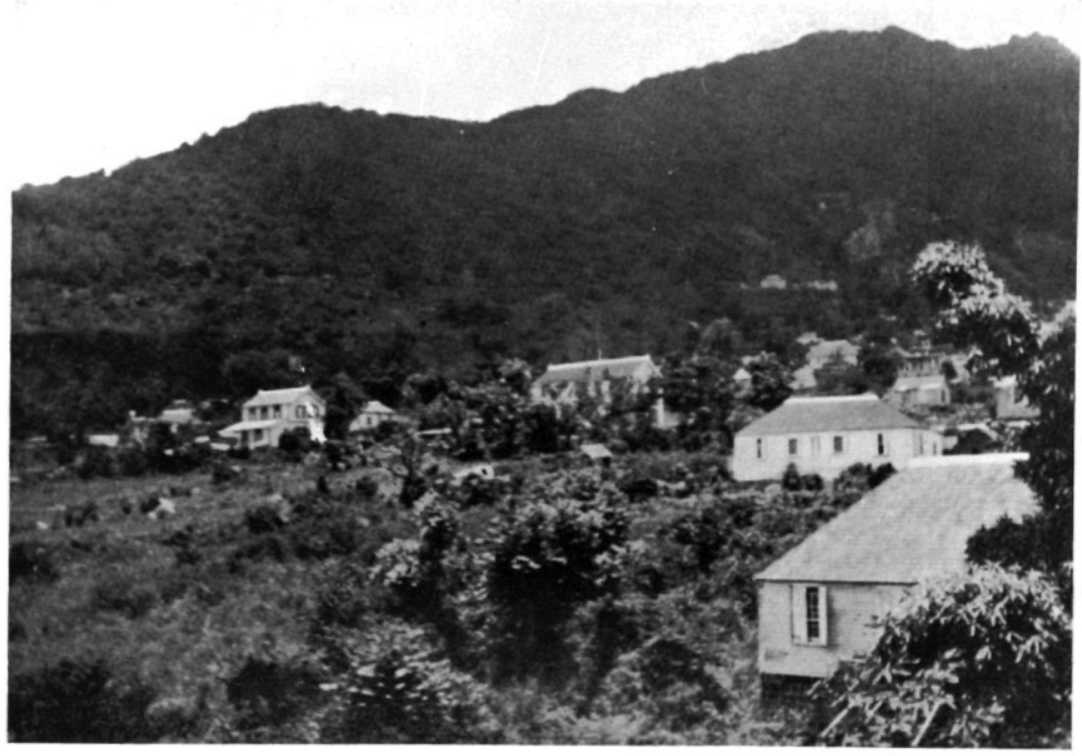

Fig. 2. Een hoekje van het dorp „The Bottom”. 


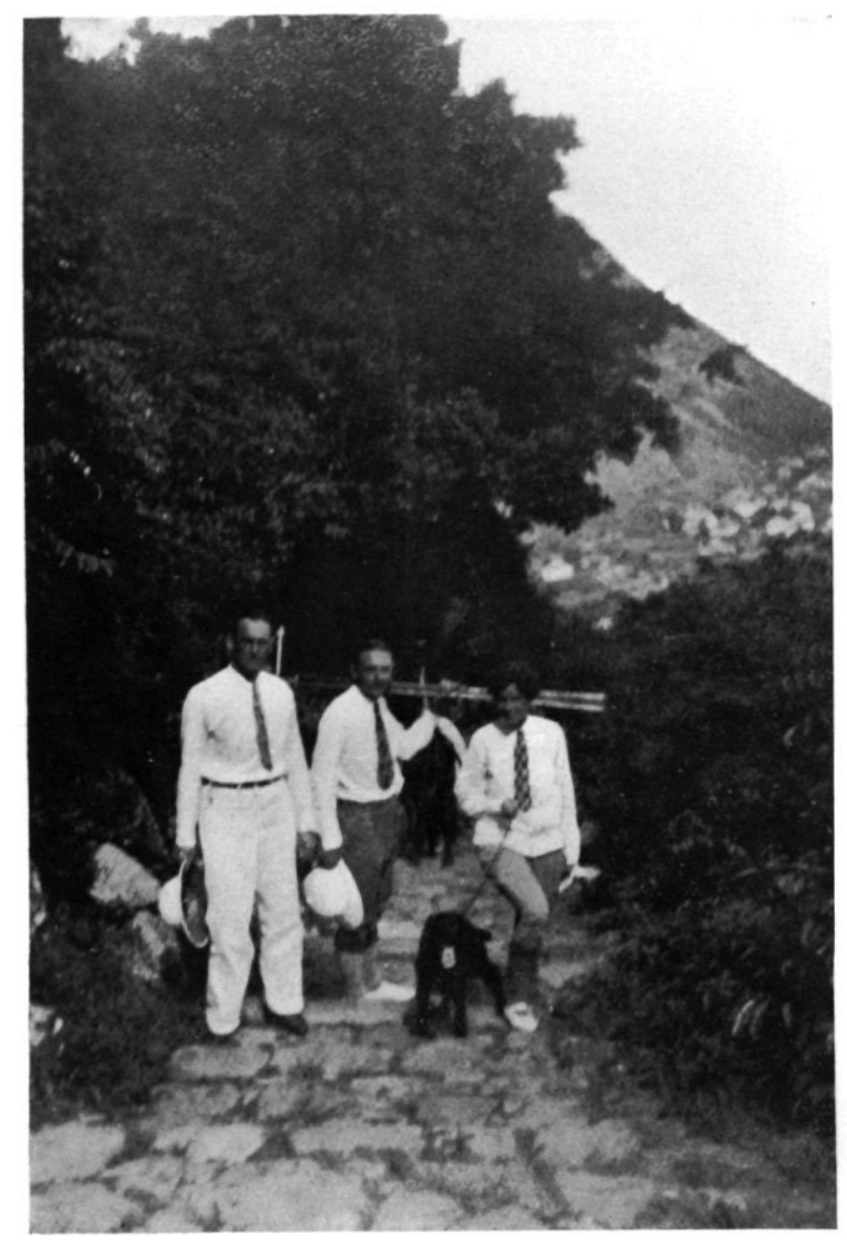

Fig. 3. Amerikaansche toeristen met fototoestel op den weg naar Windwardside. 
tin, het eiland Saba op de Engelschen. Tevens werd in hetzelfde jaar 1667 St. Eustatius op de Engelschen heroverd. Maar niet lang zouden de Hollanders in het bezit dezer eilanden blijven, want in 1672 heroverde kolonel William Stapleton, gouverneur der Engelsche eilanden beneden den wind, de eilanden Saba en St. Eustatius, en ook het eiland Tortola op de Hollanders. Het eiland St. Eustatius werd veroverd door de Engelschen met de hulp van een Fransch eskader. De Engelschman Pogson werd aangesteld als commandeur op St. Eustatius en Andruson als vice-commandeur op het eiland Saba.

Hoewel de vrede met Engeland in 1674 werd gesloten, bleven Saba en St. Eustatius in Engelsche handen, daar de Engelschen het bezit van deze eilanden wenschelijk achtten voor de verdediging van het eiland St. Kitts of St. Christopher en voor de bevordering van den handel. In dien tijd waren deze eilanden dus zoowel van strategisch als van handelsbelang.

In 1681 kwam echter een accoord tot stand tusschen koning Karel II van Engeland en de Staten-generaal van Holland, waarbij de eilanden Saba en St. Eustatius aan de Republiek werden teruggegeven.

Louis Houtcooper werd benoemd tot commandeur dezer eilanden. Hij aanvaardde het bestuur in April 1682 en werd opgevolgd door Lucas Schorer in 1686. Als vice-commandeur van Saba stelde Louis Houtcooper Jan Zeegers aan.

Zeer origineel is de notarieële akte van 21 November 1681, waarbij de helft van de eilanden Saba en St. Eustatius werd verkocht door Cornelis Demetrius, echtgenoot van Johanna Schorer, eerder weduwe van Johan Abraham van Rhee, aan de WestIndische Compagnie voor $f 3.140$.- , terwijl de andere helft dezer eilanden bij notarieële akte van 26 Juli 1683 werd verkocht voor dezelfde som door Isaak van Pere. Uit deze notarieële akten blijkt dus, dat de eilanden Saba en St. Eustatius in het particulier bezit van families waren gekomen. De verkoopsom van deze eilanden, voor elk $f$ 6.280.-, kan, ook voor dien tijd, niet hoog worden genoemd.

De door commandeur Louis Houtcooper benoemde vice-commandeur van Saba Jan Zeegers werd in October 1687 vervangen door Engel van Beverhout.

In het jaar 1688 komt er beroering op de eilanden Saba en St. Eustatius. In Augustus 1688 breekt er op St. Eustatius een opstand van slaven uit tegen de blanke bevolking, welke opstand echter gemakkelijk bedwongen werd. Op Saba was de ontevreden- 
heid meer te zoeken onder de blanke bevolking. Hun grief was gebrek aan hulp der West-Indische Compagnie in toezending van levensmiddelen en munitie. Zelfs werd door de ontevredenen gedreigd, dat zij zich bij de Engelschen zouden aanlsuiten. Deze „opstand der blanken" op Saba liep zelfs zoover, dat zij de gehoorzaamheid aan den commandeur Schorer, die in 1686 Louis Houtcooper op St. Eustatius was opgevolgd, opzegden, en er toe overgingen den op Saba dienstdoenden vice-commandeur Engel van Beverhout tot commandeur van Saba te benoemen, en Gilles Pietersz. als zijn secretaris. De blanke bevolking van Saba verklaarde zich dus onafhankelijk van den Raad van St. Eustatius, toentertijd het bestuurs- en rechtscollege voor de beide eilanden St. Eustatius en Saba.

In 1689 werd een aanval der Franschen ter verovering van Saba afgeslagen, maar het eiland St. Eustatius moest weer voor de zooveelste maal van eigenaar verwisselen, en viel op 6 April 1689 in handen der Franschen. De Hollandsche kolonisten op St. Eustatius verlieten het eiland en begaven zich gedeeltelijk naar de eilanden Nevis (Engelsch bezit), St. Thomas en Curaçao, maar de meesten gingen naar het meest dichtbijzijnde eiland Saba, dat, zooals gezegd, in Hollandsche handen was gebleven.

De commandeur Schorer op St. Eustatius was, na de verovering der Franschen van dit eiland, naar Saba gevlucht, waar de opstandige Sabanen hem zonder rancune in hun midden hadden opgenomen, en zelfs zijn autoriteit weer erkenden. De Sabanen boden Schorer ten slotte hun hulp aan bij zijn plan om van Saba uit het eiland St. Eustatius op de Franschen te heroveren. Dit plan kwam ten uitvoer op 24 Juli 1689, toen de kapitein der burgerij Jan Symonsz Doncker en zijn officier Joan Benners zich met 30 à 35 man in een boot naar St. Eustatius begaven en aldaar landden. Op 28 Juli d.a.v. vertrok de commandeur Schorer uit Saba. Kort na diens aankomst te St. Eustatius verscheen een Engelsch eskader voor het eiland onder Thornhill. De herovering van St. Eustatius met behulp der Engelschen stuitte evenwel op moeilijkheden door de voorwaarden der Engelschen. Het slot van de onderneming van Schorer was, dat de Hollanders en de Engelschen het over de herovering van St. Eustatius op de Franschen niet eens konden worden, en dat Schorer met zijn mannen weer onverrichter zake naar Saba terugkeerde. De Engelschen namen ten slotte het eiland St. Eustatius in bezit. Het duurde nog tot 1696, voordat St. Eustatius, op bevel van den koning van Engeland, aan de Hollanders werd teruggegeven. 
De toen op dat eiland aanwezige garnizoenscommandant, de Engelschman Majoor William Mussenden, gaf het eiland over aan Gilles Pietersz., die, zooals hiervoren vermeld, in 1688 door de Sabanen als secretaris van den door hen benoemden commandeur van Saba, Engel van Beverhout, was aangesteld.

In 1696 werd tot commandeur van St. Eustatius en Saba benoemd Johan Salomonsz, en tot vice-commandeur van Saba Adriaan Runnels Jr.

De commandeur Johan Salomonsz stierf in 1700, en daarna ontstond er oneenigheid over de opvolging als commandeur van St. Eustatius en Saba tusschen den kapitein der burgerij Jan Symonsz Doncker en Lucas van Beverhoudt. De eerste is hiervoren genoemd als uitvoerder van het plan-Schorer tot herovering van St. Eustatius. Gedurende korten tijd was Lucas van Beverhoudt, die zich zelf als zoodanig had uitgeroepen, commandeur. De burgerij keerde zich tegen Van Beverhoudt, en wendde zich tot Doncker, die het bestuur in handen nam.

Het bestuur van Doncker was echter van korten duur, want reeds één jaar later, in 1701, werd hij vervangen door Isaac Lamont, vroeger commissaris op Curaçao. De door Johan Salomonsz benoemde vice-commandeur van Saba, Adriaan Runnels Jr., werd op last van den Nieuwen commandeur vervangen door Jacobus Leverock.

Tot zoover de historische gebeurtenissen in de 17e eeuw, op Saba betrekking hebbende. Men heeft uit het voorgaande gezien, dat het lot van Saba nauw aan dat van St. Eustatius verbonden was. Van St. Eustatius uit werd Saba bestuurd door den hiervoren genoemden Raad van St. Eustatius, terwijl de hoogste autoriteit op Saba, de vice-commandeur, steeds door den commandeur van St. Eustatius werd benoemd, en aan dezen ondergeschikt en verantwoording verschuldigd was.

De veelvuldige oorlogen tusschen de Hollanders, Engelschen en Franschen in de 17e eeuw bleven, zooals wij gezien hebben, niet tot Europeesch territoir beperkt, maar strekten zich ook tot de overzeesche koloniën uit. Men moet hierbij in het oog houden, zooals reeds eenige malen hiervoren is vermeld, dat bij verovering van de eilanden door de vijandelijke krijgsmacht, de Hollandsche kolonisten meestal noodgedwongen de eilanden verlieten om op andere eilanden zich opnieuw te vestigen. Ook vonden gedwongen nederzettingen van gevangenen plaats op de eilanden, die dan van het eene naar het andere eiland werden overgebracht. Daar zich vele eilanden in dit deel van West-Indië bevinden, is het be- 
grijpelijk, dat op de meeste dezer eilanden de oorsprong der thans levende bevolking zeer moeilijk kan worden nagespoord. Bij persoonlijke navraag onder de vrij talrijke blanke bevolking van Saba bleek mij, dat bij de meesten de wetenschap omtrent de oorsprong van hun familie zich slechts tot hun grootouders of overgrootouders beperkte, en men zich daarna in gissingen begaf. Een Amerikaansche schrijfster heeft daarom het eiland Saba in een van haar artikelen ,the mysterious island" genoemd. De meeste Sabanen dragen Engelsche namen, en velen van hen beweren van Schotschen oorsprong te zijn, maar bewijzen kunnen zij daarvoor niet aanvoeren, en het blijft bij veronderstellingen.

Het staat evenwel vast, dat talrijke namen, die oorspronkelijk Hollandsch zijn geweest, verengelscht zijn. Als voorbeeld noem ik den naam "Sagers", een veelvuldig voorkomende naam op Saba. Men heeft in het voorgaande kunnen lezen, dat door den commandeur Louis Houtcooper als vice-commandeur van Saba werd aangesteld Jan Zeegers. Voor de hand ligt, dat deze Hollandsche naam ten slotte verengelscht werd in "Sagers". Ook bleek mij op Saba, dat de naam Sagers op verschillende wijzen werd geschreven, nl. „Zagers” of „Zagors”; wederom een bewijs van de langzame verengelsching van den vroegeren Hollandschen naam Zeegers.

Voor het verkrijgen van een kijk op de vroegere levenswijze der bewoners van het rotseiland Saba, is zeer interessant te lezen het reisverhaal van Pater J. B. Labat, geschreven in het begin van 1700, en getiteld: New journies to the French islands of America. In dit reisverhaal komt een gedeelte voor, waarbij hij o.a. het eiland Saba beschrijft. Pater Labat vertelt dan zeer levendig over de aankomst en hoe hij ontvangen werd; hoe de huizen er uitzagen, en verdere wetenswaardigheden. En wanneer men op Saba zijnde, dit reisverhaal leest, vraagt men zich af, of er eigenlijk iets veranderd is na al die vele jaren op dit eiland, meer dan twee eeuwen geleden.

Pater Labat vertelt dan verder van de vriendelijkheid en behulpzaamheid der bewoners van het eiland tegenover den vreemdeling; en verder, dat de hoogste autoriteit van het eiland hem gastvrij in zijn huis had ontvangen en hem aan zijn tafel had genoodigd; van de keurig uitziende houten huisjes der eilandbewoners; van de rood geverfde daken en de gordijnen voor de glazen ramen en de zindelijkheid binnenshuis met de glad geboende houten vloeren. En zoo is het heden ten dage nog hetzelfde. Wanneer men als vreemdeling het eiland bezoekt, valt dadelijk op 
de vriendelijkheid en de behulpzaamheid der bevolking en de bereidwilligheid tot het geven van alle mogelijke inlichtingen. Het meerendeel der houten huizen van de bevolking zijn wit geverfd en de daken rood; binnenshuis ziet alles er keurig uit, en de houten vloeren spiegelen den binnentredende tegen. En al gauw komt de vreemdeling in aanraking met den gezaghebber van het eiland, die den nieuw aangekomene gedurende zijn verblijf op het eiland van nut kan zijn door het geven van inlichtingen.

Het eiland Saba heeft twee goede landingsplaatsen, nl. één aan de zuidzijde, de Fortbaai, en één aan de westzijde, de Ladderbaai. Van elk dezer twee baaien uit voert een weg, bestaande uit gemetselde treden, naar het 800 Eng. voet boven den zeespiegel gelegen dorp ,the Bottom". Dit dorp, in een kom gelegen, omringd door hooge bergen, biedt een pittoreske aanblik door de keurig geverfde houten huisjes met goed onderhouden tuintjes er omheen, beplant met allerlei soorten bloemen en planten. De tuinen en huizen zijn meestal door stevig gemetselde muren omgeven. Deze muren, welke veelal in den slaventijd zijn gebouwd, moeten de huizen beschermen tegen eventueele watervloeden, welke bij hevigen regenval van de bergen naar beneden kunnen stroomen. Dit gevaar is werkelijk niet denkbeeldig, daar de regenval in sommige tijden van het jaar zeer hevig kan zijn.

Het mannelijk deel der bevolking leeft voor het grootste deel van land- en tuinbouw; aan veeteelt wordt in beperkte mate gedaan; verder houden zich nog eenigen met vischvangst bezig. De in vroeger tijden op Saba welbekende scheepsbouwindustrie is zoo goed als verdwenen, en beperkt zich thans tot den bouw van roei- en kleine visschersbooten. Van de vroegere schoenenindustrie, is niets meer over. Het voornaamste landbouwproduct is de Hollandsche aardappel, die van zeer goede kwaliteit is. Verder worden verschillende tuinbouwproducten verbouwd. De tuinbouw levert, vooral in de hooger en daardoor koeler en vochtiger gelegen gronden, nl. op de Windwardside, zeer goede resultaten op. De voornaamste tuinbouwproducten zijn: salade, tomaten, bieten, uien, groene kool, radijs. Eenige jaren geleden is een Tuinbouw- en Veeteeltvereeniging opgericht met gouvernements-subsidie, welke vereeniging de vele planters op het eiland door voorlichting en adviezen tot meer moderne tuinbouwen veeteeltmethodes tracht te brengen, en tevens zorg draagt voor de export van tuinbouw- en veeteeltproducten. 
Het vrouwelijk deel der bevolking houdt zich bijna zonder uitzondering met het maken van kantwerk bezig. Voor het begin der economische crisis in Amerika vond het mooie kantwerk aldaar een goede afzetmarkt, maar helaas is de crisis oorzaak, dat de export van dit luxe-artikel tot een minimum is gereduceerd.

De taal der bevolking is Engelsch. Voor het onderwijs aan de jeugd wordt zorggedragen door twee gouvernementsscholen en twee Roomsch-Katholieke bijzondere scholen, welke scholen zich beperken tot het geven van lager onderwijs.

Het eiland Saba is door zijn bijzonder natuurschoon welbekend, vooral bij de Amerikanen, waarvan velen, hetzij per stoomboot, hetzij met eigen jacht, het eiland komen bezoeken. De overtalrijke bloemen en planten van velerlei soort geven het eiland een vriendelijk aanzien. De vergezichten op de hoog gelegen punten van het eiland zijn onvergelijkelijk, over de blauwe zee rondom, met de eilanden in de nabijheid. En dan doet de groen begroeide top van den hoogsten berg bij den vreemdeling op het eiland het verlangen ontstaan, daar boven op den top van nog schooner vergezichten te genieten.

Op het eiland bevinden zich thans vier dorpen, nl. $1^{\circ}$. the Bottom ook wel Leverock's town genaamd, waar de gouvernementsgebouwen, een radiostation en het woonhuis van den gezaghebber te vinden zijn. Van the Bottom leidt een weg, wederom van gemetselde steenen treden gemaakt, naar het dorp St. Johns, ongeveer 1000 Eng. voet boven den zeespiegel gelegen, waar een prachtig uitzicht op zee en op de eilanden St. Eustatius en St. Kitts te genieten is. Van St. Johns voert de weg verder naar het derde dorp Windwardside, ongeveer 1400 Eng. voet boven den zeespiegel, waar een talrijke blanke bevolking woont, zich voornamelijk bezig houdende met tuinbouw en veeteelt. Hier vindt men ook een mooi uitzicht op de zee, met talrijke eilanden in het verschiet, zooals St. Martin, St. Barths, Nevis, Tortola. Van Windwardside naar het vierde en laatste dorp Hellsgate, ook wel Zion's Hill geheeten, leidt een prachtige weg langs grillige rotsen en mooi gevormde zeeinhammen langs de diep beneden liggende zeekust, alles weelderig met tropische gewassen begroeid. Het dorp Hellsgate, ongeveer 1600 Eng. voet boven den zeespiegel, is tegen een berghelling aan gebouwd, en ziet recht op St. Martin uit. Hier wonen ook zeer veel blanke planters, die hun gronden op de hooger gelegen 
berghellingen hebben. In de nabijheid van Hellsgate zijn de zwavelmijnen. Deze zwavelmijnen zijn een 20 jaar geleden door een buitenlandsche maatschappij geëxploiteerd. De talrijke mijngangen, thans verlaten, getuigen van harden arbeid. Van het dorp Hellsgate leidt een weg naar het nu niet meer bestaande dorp Marypoint, een nederzetting van blanken, bestaande uit slechts enkele families, die dit jaar door de zorgen van het gouvernement uit hun isolement zijn verlost, en naar the Bottom zijn overgebracht. Van Marypoint voert een mooie weg naar the Bottom, en dan is men het eiland rond geweest. Een groot gemak voor transport van den mensch over de bergpaden is het paard, terwijl de goederen veelal per ezel worden vervoerd, voor zoover deze goederen van kleine afmetingen en niet te zwaar van gewicht zijn. De groote en zware stukken worden door de negers op het hoofd naar boven en beneden vervoerd.

Over het algemeen kan worden gezegd, dat er op het eiland weinig armoede wordt geleden, hoewel de economische toestand van het eiland met zijn weinige mogelijkheden voor handel en industrie niet zeer gunstig kan worden genoemd.

De meeste ingezetenen van het eiland hebben een eigen huisje met een stuk grond; en velen nog eenige stuks vee. De meesten bezitten een aantal geiten, die in grooten getale, gedeeltelijk in verwilderden staat, op het eiland rondloopen. Op hun stuk grond verbouwen de menschen de noodige maïs, aardappelen, en andere tuinbouwproducten voor het dagelijksch levensonderhoud. Verder houden zich nog een aantal menschen met de visscherij onledig. De Sabanen zijn welbekend als uitstekende zeelui. Vele Sabanen varen als kapitein of stuurman op Amerikaansche stoombooten.

Zooals reeds hierboven gezegd, was het aantal inwoners van het eiland in het jaar 1933 ongeveer 1450; daarvan is ongeveer de helft blank. De statistiek over de laatste jaren leert ons een kleine, maar gestadige teruggang van het inwonertal: in 1900 was dit ongeveer 2100 zielen en 30 jaar later ongeveer 1650 zielen. De teruggang van het aantal geboorten is te zoeken bij de blanke bevolking, terwijl het aantal geboorten bij de gekleurde bevolking eerder toenemende is.

Ongeveer de helft der bevolking belijdt den Anglikaanschen en de andere helft den Roomsch-Katholieken godsdienst.

Het gouvernement van Curaçao doet de laatste jaren, onder den tegenwoordigen gouverneur Zijne Excellentie Van Slobbe, al 
het mogelijke om in den economischen toestand op de drie bovenwindsche eilanden St. Martin, Saba en St. Eustatius de noodige verbetering te verkrijgen. Wij noemen voor Saba speciaal de oprichting van de tuinbouw- en veeteeltvereeniging met gouvernements-subsidie; de veertiendaagsche stoombootverbinding met Curaçao, eveneens met gouvernements-subsidie, ter vervanging van de vroegere ongeregelde en onzekere zeilschoenerverbinding; de oprichting van een radiostation; en talrijke andere pogingen om bestaande industrieën (b.v. de kantwerkindustrie) te bevorderen of nieuwe industrieën te scheppen. Dit alles wordt door de bevolking op hoogen prijs gesteld.

Zeer zeker wordt de band, welke Nederland als koloniale mogendheid met de bevolkingsgroepen van West-Indië verbindt, door de bovenvermelde bestuursdaden nauwer aangehaald, en gevoelen ook de bewoners van de bovenwindsche eilanden zich daardoor steeds meer tot de Nederlandsche driekleur aangetrokken. 